University of Nebraska - Lincoln

DigitalCommons@University of Nebraska - Lincoln

November 1976

\title{
Piezomodulated and specular reflection spectra of a polydiacetylene crystal
}

\author{
Craig J. Eckhardt \\ University of Nebraska - Lincoln, ceckhardt1@unl.edu \\ H. Muller \\ University of Nebraska - Lincoln \\ J. Tylicki \\ University of Nebraska - Lincoln \\ R.R. Chance \\ Allied Chemical Corporation, Morristown, New Jersey
}

Follow this and additional works at: https://digitalcommons.unl.edu/chemistryeckhardt

Part of the Chemistry Commons

Eckhardt, Craig J.; Muller, H.; Tylicki, J.; and Chance, R.R., "Piezomodulated and specular reflection spectra of a polydiacetylene crystal" (1976). Craig J. Eckhardt Publications. 39.

https://digitalcommons.unl.edu/chemistryeckhardt/39

This Article is brought to you for free and open access by the Published Research - Department of Chemistry at DigitalCommons@University of Nebraska - Lincoln. It has been accepted for inclusion in Craig J. Eckhardt Publications by an authorized administrator of DigitalCommons@University of Nebraska - Lincoln. 


\title{
LETTERS TO THE EDITOR
}

The Letters to the Editor section is subdivided into four categories entitled Communications, Notes, Comments and Errata. The textual material of each Letter is limited to 1200 words minus the following: (a) 200 words for a square figure one-column wide. Larger figures are scaled in proportion to their area. (b) 50 words for each displaved equation: (c) 7 words for each line of table including headings and horizontal rulings. Proof will be sent to authors. See the issue of 1 July 1976 for a fuller description of Letters to the Editor.

\section{COMMUNICATIONS}

\section{Piezomodulated and specular reflection spectra of a polydiacetylene crystal ${ }^{*}$}

\author{
C. J. Eckhardt, H. Müller, and J. Tylicki \\ Department of Chemistry, University of Nebraska, Lincoln, Nebraska 68588 \\ R. R. Chance \\ Materials Research Center, Allied Chemical Corporation, Morristown, New Jersey 07960 \\ (Received 28 July 1976)
}

A class of potential quasi-one-dimensional organic conductors ${ }^{1}$ is the monocrystalline polydiacetylenes. These polymers can be obtained as single crystals that have high structural perfection and a chain configuration that permits extensive $\pi$-electron delocalization. ${ }^{2}$ The poly-2, 4-hexadiyne-1,6-diol-bis-( $p$-toluene sulfonate) (PTS) has been the most extensively studied system and interest centers upon the extent of delocalization along the two chains comprising the $P 2_{1} / c$ unit cell. ${ }^{3}$

The optical spectra of PTS are of current interest because of reports that the reflection bands of the PTS crystal at $298 \mathrm{~K}$ are observed to "double" near $200 \mathrm{~K}^{4-7}$ and undergo increasing splitting and red shift with decreasing temperature. The lowest energy band is reported to split into two bands (I at $\sim 15700 \mathrm{~cm}^{-1}$ and II at $\sim 16000 \mathrm{~cm}^{-1}$ ) which have a maximum separation of $300 \mathrm{~cm}^{-1}$ at $4 \mathrm{~K}$. A shoulder is observed on the blue side of II. Resonance Raman studies with excitations in I and II indicate that the bands are not electronically coupled. ${ }^{7}$

The splitting has been given two interpretations: (1) The splitting arises from differing local backbone structures arising from a polaron mechanism ${ }^{7}$; and (2) a Wannier exciton band model of the individual chains which, when considered with the fact that there are two translationally inequivalent chains in the unit cell, leads to a splitting arising from interchain coupling. ${ }^{5}$ The latter is equivalent to the model for the Davydov splitting of Frenkel excitons and must be rejected because the polarizations of $I$ and $I I$ are identical. The interchain distance of $\sim 7.5 \AA$ also indicates minimal interaction between the chains.

The remaining polaron mechanism requires disappearance of the splitting at $300 \mathrm{~K} .{ }^{7}$ Thus, determination of the absence or presence of splitting at $300 \mathrm{~K}$ would test the hypothesis.
Modulated piezoreflection spectra ${ }^{8}$ have been found useful in detecting structure which usually may only be observed at low temperature. ${ }^{9}$ Such a modulation of the crystal lifts the van Hove singularities from the background and, in favorable cases, the resulting structure may be used as an indication of the dimensionality of the band. ${ }^{8}$ The near normal incidence piezomodulated and specular reflection spectra of PTS polarized in the chain direction have been obtained at $300 \mathrm{~K}$ and are shown in Fig. 1. The spectra were obtained at $50 \mathrm{~cm}^{-1}$ intervals by using ensemble averaging. The $200 \mathrm{~Hz}$ strain of $\sim 10^{-4}$ was in the chain direction. The results are in agreement for the several crystals studied.

The piezomodulation spectrum shows that the doubled structure is maintained at $300 \mathrm{~K}$. This may be understood by recognizing that the piezomodulation spectrum approximates a derivative of the reflection spectrum. The critical point structures are strongly emphasized and thus structure may be observed that would not be obtained by differentiation of the reflection spectrum. ${ }^{8}$

Because of the prominence of the structure of the piezomodulated spectrum, the reflection spectrum was

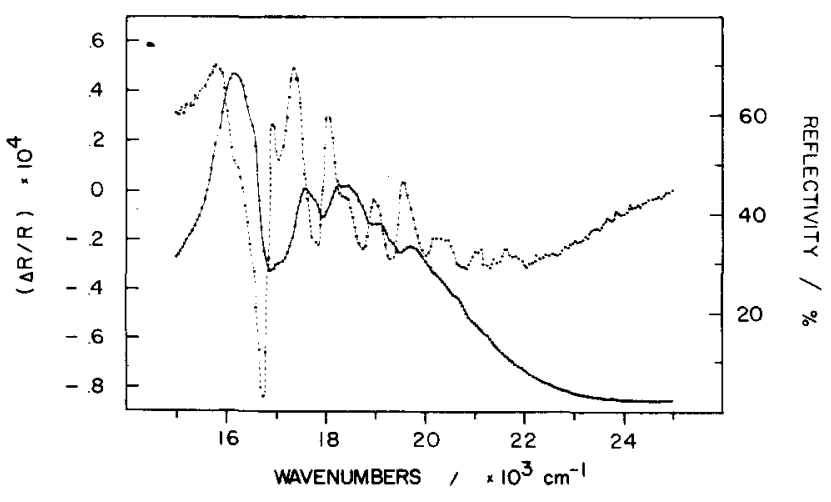

FIG. 1. Direct (solid line) and piezomodulated (dashed line) reflection spectra of PTS at $300 \mathrm{~K}$. Bandpass is $30 \mathrm{~cm}^{-1}$ 


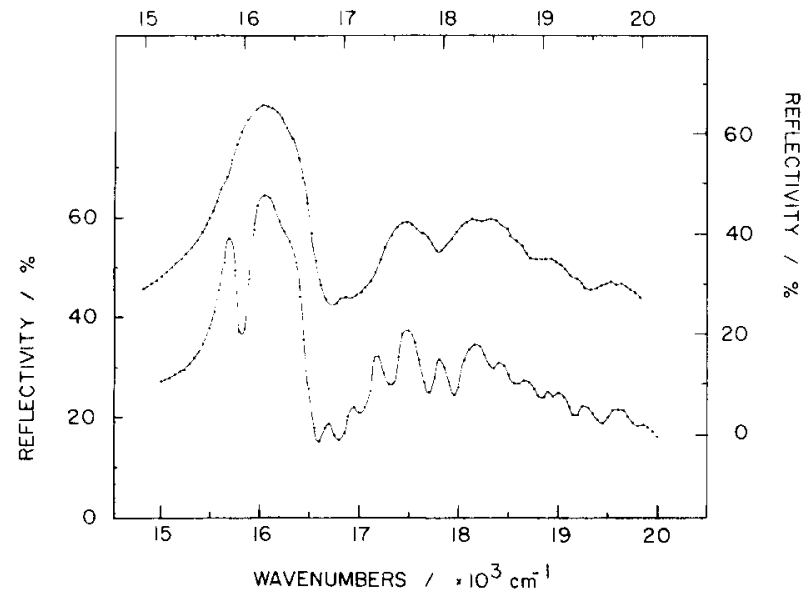

FIG. 2. $300 \mathrm{~K}$ (upper) and $77 \mathrm{~K}$ (lower) reflection spectra of PTS. Note change of registration of upper and lower wavenumber axes. Bandpass is $30 \mathrm{~cm}^{-1}$ (lower scale for lower curve, upper scale for upper curve).

obtained at $77 \mathrm{~K}$ at resolution equivalent to the $300 \mathrm{~K}$ work. This spectrum has structure equivalent to those reported at $9 \mathrm{~K}^{5}$ and $4 \mathrm{~K}^{7}$. When this spectrum is compared to the $300 \mathrm{~K}$ spectrum (Fig. 2), it is seen that, aside from the red shift due to contraction on cooling, the $300 \mathrm{~K}$ spectrum is the thermally broadened envelope of the $77 \mathrm{~K}$ spectrum. The structures at 17000 and $17250 \mathrm{~cm}^{-1}$ at $300 \mathrm{~K}$ clearly relate to the peaks at 16700 and $16950 \mathrm{~cm}^{-1}$ at $77 \mathrm{~K}$. Also convincing is the system centered at $18400 \mathrm{~cm}^{-1}$ at $300 \mathrm{~K}$ which can be seen to be the envelope of the $77 \mathrm{~K}$ bands at 18175,18425 , and $18675 \mathrm{~cm}^{-1}$. Such agreement may be found throughout the band.

Careful examination of the intense low energy peak at $161800 \mathrm{~cm}^{-1}$ reveals inflections in the band near 15840 and $16440 \mathrm{~cm}^{-1}$ for the $300 \mathrm{~K}$ reflection spectrum. These values are in excellent agreement with the struc- tures observed at 15830,16230 , and $16500 \mathrm{~cm}^{-1}$ in the piezomodulation spectrum. By adding the $200 \mathrm{~cm}^{-1}$ thermal shift to the corresponding structures in the $77 \mathrm{~K}$ spectrum 15880,16250 , and $16500 \mathrm{~cm}^{-1}$ are obtained. Similar comparisons can be made through the entire spectral region.

Thus the doubled structure results from decreased thermal broadening and is thereby a normal phenomenon. However, the explanation of this rich spectrum is a problem at any temperature since it cannot be fit by straightforward theoretical treatments. ${ }^{10}$ Need of additional study is necessary wherein attention may be focused upon the detailed structure of the chain. For example, the chains may have a bimodal distribution of lengths which would rationalize the "doublet" structure. ${ }^{11}$ Also, it remains to be seen if the splitting is a property of all polydiacetylenes or is unique to PTS.

* Supported in part by Solid State Chemistry Program of the National Science Foundation.

${ }^{1}$ E. P. Goodings, Chem. Soc. Rev. 5, 95 (1976).

${ }^{2} \mathrm{G}$. Wegner, Makromol. Chem. 145, 85 (1971); R. H. Baughman, J. Polym. Sci. Polym. Phys. Ed. 12, 1511 (1974).

${ }^{3}$ D. Kobelt and E. F. Paulis, Acta Crystallogr. B 30, 232 (1973).

${ }^{4}$ D. Bloor, D. J. Ando, F. H. Preston, and G. C. Stevens, Chem. Phys. Lett. 24, 407 (1974).

${ }^{5}$ B. Reimer, H. Bässler, J. Hesse, and G. Weiser, Phys. Status Solidi B 73, 709 (1976).

${ }^{6}$ D. N. Batchelder and D. Bloor, Chem. Phys. Lett. 38, 37 (1976).

${ }^{7}$ D. Bloor, F. H. Preston, and D. J. Ando, Chem. Phys, Lett. 38, 33 (1976).

${ }^{8}$ M. Cardona, Modulation Spectroscopy, edited by F. Seitz, D. Turnbull, and H. Ehrenreich (Academic, New York, 1969).

${ }^{9}$ C. J. Eckhardt and J. Merski, Surf. Sci. 37, 937 (1973); Phys. Rev. Lett. (submitted).

${ }^{10} \mathrm{E}$. G. Wilson, J. Phys. C 8, 727 (1975).

${ }^{11}$ G. J. Exharos, W. M. Risen, Jr., and R. H. Baughman, J. Am. Chem. Soc. 98, 481 (1976).

\title{
How much do multiple electronic surfaces influence chemical reactivity? $\mathrm{F}+\mathrm{H}_{2}$ : A case study*
}

\author{
Andrew Komornicki, Thomas F. George, ${ }^{\dagger}$ and Keiji Morokuma \\ Department of Chemistry, The University of Rochester, Rochester, New York 14627 \\ (Received 25 August 1976)
}

One of the major goals of chemical dynamics has been the accurate prediction of the rates and factors influencing chemical reactions. In recent years, various models and theories with varying levels of sophistication have been developed. Although each of these approaches has its limitations and approximations, a common factor in nearly all approaches has been the assumption that the interaction potential can be adequately represented by the lowest adiabatic Born-Oppenheimer potential surface. For many reactions it is well known that there are low-lying electronic surfaces that could strongly couple and thereby influence the interaction potential, thus possibly altering the chemical dynamics and the resulting predicted cross sections. ${ }^{1}$

The reaction of fluorine atoms with molecular hydrogen is probably the most studied chemical reaction in recent years owing to its prominent role as the primary pumping reaction in the FH chemical laser. ${ }^{2}$ It is also 